\title{
EFFects of Flavin7 on ALLERgen Induced Hyperreactivity of AIRWAYS
}

\author{
S. Franova ${ }^{1}$, M. Joskova ${ }^{1}$, E. Novakova ${ }^{2}$, K. Adamicova ${ }^{3}$, M. Sutovska ${ }^{1}$, S. Nosal ${ }^{4}$ \\ ${ }^{1}$ Department of Pharmacology, ${ }^{2}$ Department of Microbiology and Immunology, ${ }^{3}$ Department of Pathological Anatomy, and \\ ${ }^{4}$ Pediatric Clinic, Jessenius Faculty of Medicine, Comenius University, Martin, Slovakia
}

\begin{abstract}
Some studies have suggested that the polyphenolic compounds might reduce the occurrence of asthma symptoms. The aim of our experiments was to evaluate the effects of 21 days of the flavonoid Flavin 7 administration on experimentally induced airway inflammation in ovalbumin-sensitized guinea pigs. We assessed tracheal smooth muscle reactivity by an in vitro muscle-strip method; changes in airway resistance by an in vivo plethysmographic method; histological picture of tracheal tissue; and the levels of interleukin 4 (IL-4), and interleukin 5 (IL-5) in bronchoalveolar lavage fluid (BALF). Histological investigation of tracheal tissue and the concentrations of the inflammatory cytokines IL-4 and IL-5 in BALF were used as indices of airway inflammation. Administration of Flavin7 caused a significant decrease of specific airway resistance after histamine nebulization and a decline in tracheal smooth muscle contraction amplitude in response to bronchoconstricting mediators. Flavin7 minimized the degree of inflammation estimated on the basis of eosinophil calculation and IL-4 and IL-5 concentrations. In conclusion, administration of Flavin 7 showed bronchodilating and anti-inflammatory effects on allergen-induced airway inflammation.
\end{abstract}

Key words: airways hyperresponsiveness, ovalbumin, Flavin 7

\section{INTRODUCTION}

Some epidemiologic studies have suggested that the dietary factors, including the consumption of food containing polyphenolic compounds, might reduce the occurrence of asthma symptoms. Flavonoids, a family of polyphenols, are found especially in fruits, vegetables, red wine, and tea [1]. Flavonoids have different pharmacodynamic activities. In the respiratory tract, in addition to their well-known antioxidant properties, they also have antiallergic, anti-inflammatory, and bronchodilatory effects, which might explain their beneficial effects in asthma, reported in some studies [2].

The flavonoids khellin, hispidulin, luteolin, and isoquercitrin are known for their bronchodilatory properties $[3,4,5,6]$. Qercetin and isoquercitrin decrease the eosinophil and IL-5 levels in lung homogenate and in bronchoalveolar lavage fluid (BALF) in ovalbumin immunized mice [7]. Sanbongi et al [8] confirmed that oral administration of the polyphenolic phytochemical rosmarinic acid inhibited an allergic reaction in mice, possibly through the amelioration of increases in inflammatory cytokines, chemokines, and allergen-specific antibodies. On the other hand, some other experimental and epidemiological studies do not provide clear evidence that dietary intake of flavonoids protects against asthma or chronic sputum production [9].

The aim of the present experiments was to evaluate the effects of Flavin7 on allergen-induced experimental inflammation of airways in ovalbumin-sensitized guinea pigs. We addressed the issue by an in vitro muscle-strip method; changes in airway resistance by an in vivo plethysmographic method; histological picture of tracheal tissue; and the levels of interleukin 4 (IL-4), and interleukin 5 (IL-5) in BALF.

\section{Material AND Methods}

The study was approved by the Ethics Committee of the Jessenius Faculty of Medicine in Martin, Slovakia. Guinea pigs (200-250 g) were randomly divided into 3 experimental groups: Group 1 - sensitized to ovalbumin (OVA) and treated for 21 days with saline; Group 2 - sensitized to OVA and treated for 21 days with Flavin 7 in a dose of $2 \mathrm{ml} / \mathrm{kg}$; and Group 3 - control, treated for 21 days with saline only. The number of animals in each experimental group was 10 .

Three weeks after sensitization, the following parameters were investigated: tracheal smooth muscle reactivity by an in vitro muscle-strip method; changes in airways resistance by an in vivo plethysmographic method; histological picture of the tracheal tissue; and the levels of interleukin 4 (IL-4), and interleukin 5 (IL5) in BALF.

Flavin $7^{\circledR}$ was a gift from Vita Crystal Slovakia (Slovakia). It contains $196 \mathrm{mg}$ of flavonoids mixture and $0.2 \mathrm{mg}$ of resveratrol in $10 \mathrm{ml}$. OVA (egg albumin grade III), histamine, acetylcholine, and other chemicals were purchased from Sigma Chemicals (Germany). Mouse IL-4, IL-5 ELISA kits for protein array systems were purchased from BioTech X-ray (St. Louis, MO)

\section{Sensitization of Guinea Pigs}

Male Trik guinea pigs (200 - 250g) were actively sensitized by administration of ovalbumin. Five milligram 
of OVA, with $1 \mathrm{mg}$ of aluminium hydroxide, was injected i.p. along with $5 \mathrm{mg}$ OVA s.c. in $1 \mathrm{ml}$ of saline on Day 1. Subsequently guinea pigs were treated for 21 days with repeated i.p. OVA injections every 3 days and exposed to OVA ( $1 \%$ in $0.9 \%$ sterile sodium chloride) in an aerosol chamber for the last 6 days everyday.

\section{Evaluation of Airway Reactivity}

In vitro, reactivity of the tracheal smooth muscle was estimated in a preparation of tracheal strips. They were placed in a $20 \mathrm{ml}$ organ chamber containing Krebs-Henseleit buffer, maintained at $36.5 \pm 0.5^{\circ} \mathrm{C}$ and $\mathrm{pH}$ of $7.5 \pm 0.1$, aerated continuously with a mixture of $95 \% \mathrm{O}_{2}$ and $5 \% \mathrm{CO}_{2}$. The amplitude of contraction $(\mathrm{mN})$ of tracheal muscle strips in response to the cumulative doses of histamine $\left(10^{-8}-10^{-3} \mathrm{~mol} / \mathrm{l}\right)$ and acetylcholine $\left(10^{-8}-10^{-3} \mathrm{~mol} / \mathrm{l}\right)$ was used as an index of tracheal smooth muscle reactivity.

In vivo, airway reactivity was evaluated using a double chamber whole body plethysmograph (Rodents Double-Chamber Plethysmograph, Hugo Sachs Elektronik-Harvard Apparatus, March-Hugstetten, Germany). Specific airway resistance and its changes after a short-term inhalation (2 $\mathrm{min}$ ) of the bronchoconstricting mediator histamine - $10^{-6} \mathrm{~mol} / \mathrm{l}$ in saline were considered as indicators of reactivity [10]. For comparison, reactivity after nebulization of saline was used. There was an interval of minimum 5 min between exposures during which fresh air was insufflated into the nasal chamber.

\section{MEASUREMENT OF INFLAMMATORY CYTOKINES}

The left lung was lavaged with $0.9 \% \mathrm{NaCl}\left(37^{\circ} \mathrm{C}\right)$ $2 \times 10 \mathrm{ml} / \mathrm{kg}$ and BALF was centrifuged at $1500 \mathrm{rpm}$ for $10 \mathrm{~min}$. The supernatant was stored for subsequent biological analysis. The levels of IL-4 and IL-5 were determined by ELISA method in BALF by using commercially available kits (BioTech X-ray (St. Louis, MO). The minimum detectable level of cytokines was less than $1 \mathrm{pg} / \mathrm{ml}$.

\section{Histological ExAMINATION}

The trachea was fixed in $4 \%$ buffered formaldehyde. The sections were then stained with hematoxylin and eosin for light microscopy examination. The degree of inflammation was estimated on the basis of eosinophil calculation (mild - up to 20; medium - up to 50; strong - over 50).

\section{DATA ANALYSIS}

All results are expressed as means \pm SE. Statistical analysis was performed using one-way analysis of variance ANOVA. Differences were considered statistically significant when $\mathrm{P}$ was less than 0.05 .

\section{RESULTS}

The 3-week long treatment of OVA sensitized guinea pigs with Flavin 7 inhibited the contraction induced by cumulative doses of both histamine (Fig. 1A) and acetylcholine (Fig. 1B). The treatment also caused a significant decrease in specific airway resistance after histamine nebulization (Fig. 2) and decreases in IL-4 (Fig. 3A) and IL-5 (Fig. 3B) levels in BALF.

Histological examination of tracheal mucosa of guinea pigs after OVA sensitization revealed eosinophilic infiltration of the epithelium and submucosa. The degree of inflammation found in the OVA group treated with saline was: $3 \times$ mild and $4 \times$ medium.

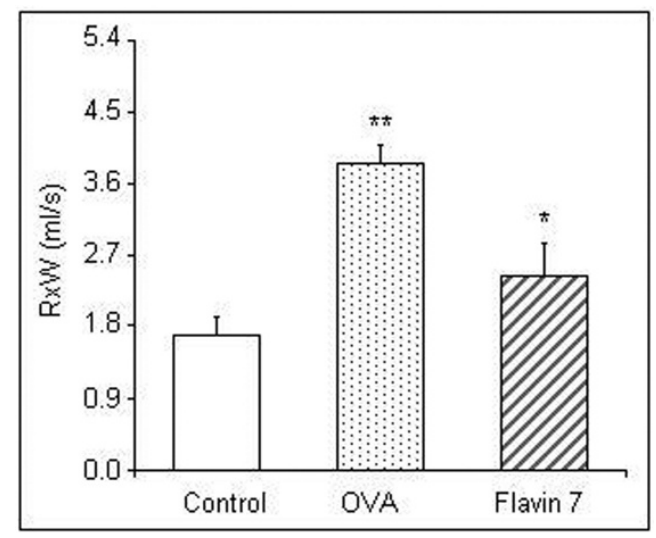

Fig. 2. Comparison of specific airway resistance after inhalation of histamine $\left(10^{-6} \mathrm{~mol} / \mathrm{l}\right)$ in the control, OVA-sensitized, and OVA-sensitized treated with Flavin7 guinea pigs. Data are means \pm SE; $\mathrm{n}=10$ for each group; $* \mathrm{P}<0.05$ and $* * \mathrm{P}<0.01$

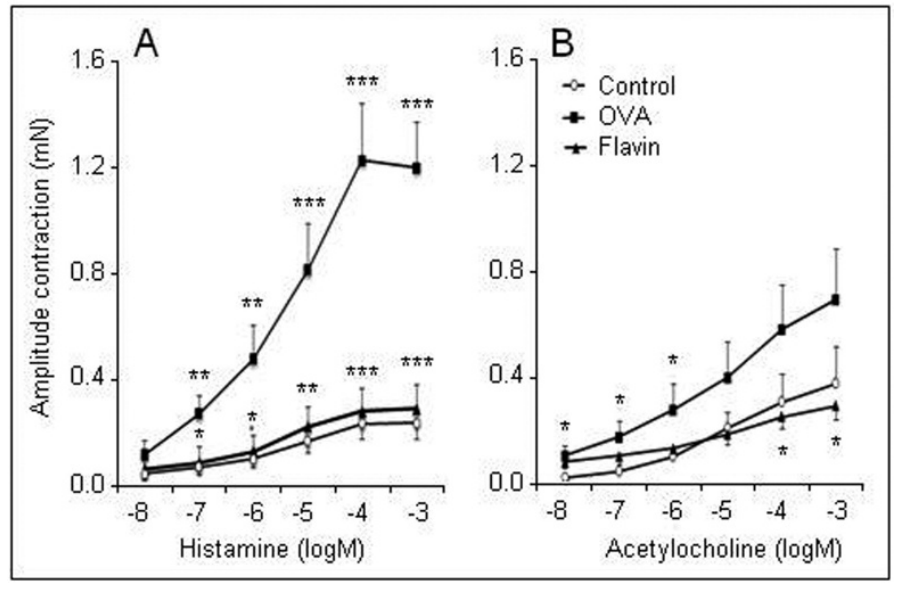

Fig. 1. Changes in the amplitude of tracheal smooth muscle contraction to histamine (Panel A) and acetylcholine (Panel B) after 21 days' treatment with Flavin7 in guinea pigs sensitized with ovalbumin (OVA). Control group (guinea pigs treated with saline only); OVA-sensitized group (guinea pigs after 21 days' OVA treatment; OVA-sensitized Flavin7-treated group (OVA-sensitized guinea pigs treated for 21 days with Flavin7). Data are means \pm SE; $\mathrm{n}=10$ for each group; $* \mathrm{P}<0.05$, $* * \mathrm{P}<0.01$, $* * * \mathrm{P}<0.001$. 


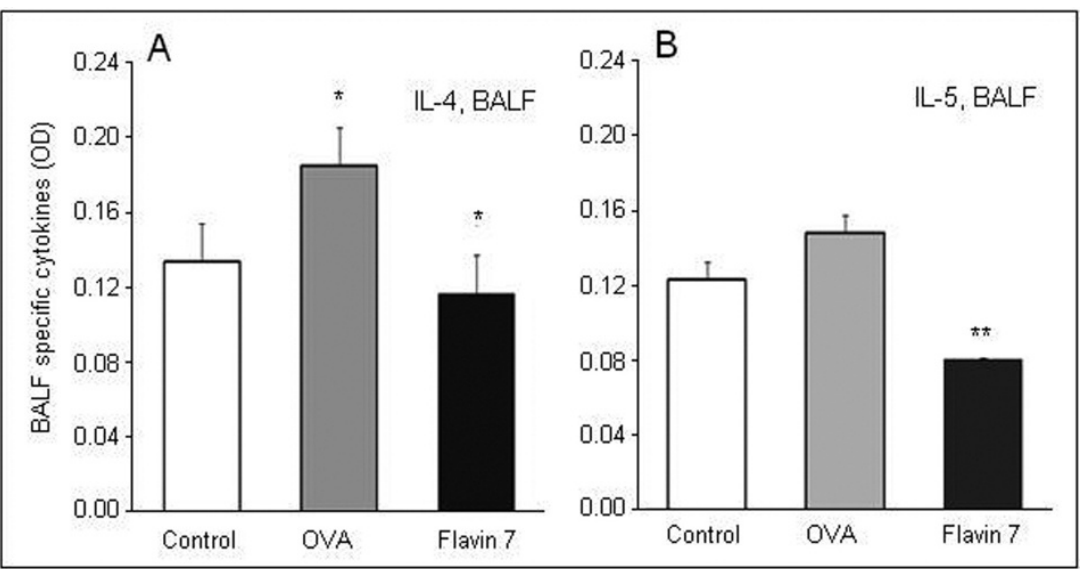

Fig. 3. Comparison of the levels of inflammatory cytokines IL-4 (Panel A) and IL-5 (Panel B) in BALF in the control, OVA-sensitized, and OVA-sensitized treated with Flavin7 guinea pigs. Data are means $\pm \mathrm{SE} ; \mathrm{n}=10$ for each group; $* \mathrm{P}<0.05$.
Agglomeration of eosinophils formed micro-abscess in the epithelium. In contrast, in the OVA group treated with Flavin7, there was a partial resolution of the eosinophilic infiltrations, so that the degree of inflammation was lowered to $3 \mathrm{x}$ mild and $1 \mathrm{x}$ medium.

\section{DisCUSSION}

Allergic asthma is a chronic inflammatory disease of the airways. Characteristic features of allergic asthma are allergen-induced early and late bronchial obstructive reactions, airway inflammation, and structural changes to the airway wall associated with airway hyperresponsiveness (AHR) and with progressive decline in lung function [11].

AHR is defined as an exaggerated obstructive response of the airways to a variety of pharmacological, chemical, and physical stimuli [12]. In the present study, we found that Flavin7 is able to minimize AHR. Flavin 7 decreased the amplitude of contraction in response to histamine and acetylcholine of tracheal smooth muscle strips prepared from OVA-sensitized guinea pigs. Furthermore, Flavin 7 treatment caused a significant decrease in specific airway resistance during histamine nebulisation, measured in a whole body plethysmograph.

Inflammatory changes during allergic reaction of airways are linked with elevated levels of $\mathrm{IgE}$ causing mast cell activation. The immunological processes involved are characterized by proliferation and activation of Th2 lymphocytes. The Th2-mediated allergic inflammation is accomplished with cytokines, such as IL-4 and IL-13 for their role in directing B lymphocytes to synthesize IgE, IL-5 for its role in maturation and activation of eosinophils, and IL-3 and IL-10 for their role in mast cell genesis [13]. Flavin7 treatment appeared to be able to ameliorate the increases in the inflammatory IL- 4 an IL- 5 cytokines. The bronchodilating and anti-inflammatory properties of Flavin 7 point to the possibility of its being an adjuvant therapeutic option in airway hyperresponsiveness in asthmatic subjects. In conclusion, the present study suggests that chronic treatment with Flavin 7 has a protective effect on airway hyperreactivity related to allergic inflammation.
Acknowledgements: Supported by Grant VEGA 1/0073/08, APVV-0030-07, VEGA 1/0072/08.

Conflicts of interest: The authors had no conflicts of interest to declare in relation to this article.

\section{REFERENCES}

[1] Ross JA, Kasum ChM. Dietary flavonoids: bioavailability, metabolic effects, and safety. Annu Rev Nutr 2002; 22: 19-34.

[2] Homma M, Minami M, Taniguchi C, Oka K, Morita S, Niitsuma T, Hayashi T. Inhibitory effects of lignans and flavonoids in saiboku-to, a herbal medicine for bronchial asthma, on the release of leukotrienes from human polymorphonuclear leukocytes. Planta Med 2000; 66: 88-91.

[3] Kennedy MCS, Stock JPP. The bronchodilator action of khelin. Thorax 1952; 7: 43-65.

[4] Hazekamp A, Verpoorte R, Panthong A. Isolation of a bronchodilator flavonoid from the Thai medicinal plant Clerodendrum petasites. J Ethnopharmacol 2001; 78: 4549.

[5] Das M, Ram A, Ghosh B. Luteolin alleviates bronchoconstriction and airway hyperreactivity in ovalbumin sensitized mice. Inflamm Res 2003; 52: 101-106.

[6] Fernandez J, Reyes R, Ponce $\mathrm{H}$ et al. Isoquercitrin from Argemone platyceras inhibits carbachol and leukotriene D4-induced contraction in guinea pigs airways. Eur J Pharmacol 2005; 522: 108-115.

[7] Rogerio AP, Kanashiro A, Fontanari C, da Silva EVG, Lucisano-Valim YM, Soares EG, Faccioli LH. Anti-inflammatory activity of quercetin and isoquercitrin in experimental murine allergic asthma. Inflamm Res 2007; 56: 402-408.

[8] Sanbongi C, Takano H, Osakabe N, Sasa N, Natsume M, Yanagisawa $\mathrm{R}$, Inoue $\mathrm{K}$, Sadakane $\mathrm{K}$, Ichinose $\mathrm{T}$, Yoshikawa T. Rosmarinic acid in perilla extract inhibits allergic inflammation induced by mite allergen, in a mouse model. Clin Exp Allergy 2004; 34: 971-977.

[9] Garcia V, Arts ICW, Sterne JAC, Thompson RL, Shaheen SO. Dietary intake of flavonoids and asthma in Adults. Eur Respir J 2005; 26: 449-452.

[10] Mokry J, Nosalova G. Evaluation of the cough reflex and airway reactivity in toluene- and ovalbumin- induced airway hyperresponsiveness. J Physiol Pharmacol 2007; 58 Supl 5: 419-426.

[11] Mokry J, Mokra D, Nosalova G, Beharkova M, Feherova Z. Influence of selective inhibitors of phosphodiesterase 3 and 4 on cough and airway reactivity. J Physiol Pharmacol 2008; 59 Suppl 6: 473-482. 
[12] Meurs H, Gosens R, Zaagsma J. Airway hyperresponsiveness in asthma: lessons from in vitro model systems and animal models. Eur Respir J 2008; 32: 487-502.

[13] Kips JC, Anderson GP, Fredberg JJ, Herz U, Inman MD, Jordana M, Kemeny DM, Lötvall J, Pauwels RA, Plopper CG, Schmidt D, Sterk PJ, Van Oosterhout AJM, Vargaftig BB, Chung KF. Murine models of asthma. Eur Respir J 2003; 22: 374-382.
Corresponding author:

Dr. Sona Franova

Department of Pharmacology

Jessenius Faculty of Medicine

Comenius University

Sklabinská 26 St.

03659 Martin, Slovakia.

Phone: +421 434132535

E-mail: Franova@jfmed.uniba.sk 